\title{
Underutilization of neuropsychology in traumatic brain injury rehabilitation: Is managed care to blame?
}

\author{
Philip Schatz ${ }^{\mathrm{a}, *}$, Lucinda J. Hughes ${ }^{\mathrm{a}}$ and \\ Douglas L. Chute ${ }^{b}$ \\ a Department of Psychology, Saint Joseph's \\ University, Philadelphia, PA 19131, USA \\ ${ }^{\mathrm{b}}$ Drexel University, Psychology Department, \\ Philadelphia, PA 19104, USA
}

\begin{abstract}
We evaluated factors determining which individuals received neuropsychological evaluations (NPEs) following traumatic brain injury (TBI). Comprehensive records from a Statewide/sponsored Head Injury Program were followed from 1985-1995 to monitor effects of managed care on provision (or absence) of formal NPEs and ultimately on rehabilitation outcome. Only $26 \%$ of 273 individuals received NPEs (within their first three years post-injury). In the years prior to and after large changes in managed care, there were no differences in the provision of formal NPEs. Discriminant analysis identified functional status at discharge from primary rehabilitation and total number of rehabilitation facilities as the two variables that most distinguished those who had received NPEs with $69 \%$ classification accuracy. Between group analyses revealed that individuals were more likely to receive NPEs if they were young, involved in liability claims, attended multiple rehabilitation facilities, or had higher functional status at discharge from primary rehabilitation, regardless of the nature or severity of their TBI. Individuals receiving formal NPEs ultimately achieved higher levels of functional independence, suggesting a potential selection bias. Individuals were no more likely to receive NPEs according to insurance status (private versus government assisted) or as a function of the decade of their injury (1980's versus 1990's). It appears that health-care reform has had no deleterious effect on neuropsychologists' ability to provide consultative services for this population, and following TBI, only a discrete sample of individuals receive and benefit from NPEs.
\end{abstract}

Keywords: Neuropsychology, assessment, rehabilitation, brain injury, managed care

\section{Introduction}

Traumatic brain injury (TBI) is a major cause of death and disability, accounting for more than half of the overall injury death rate in the United States [15]. A summary of epidemiological studies identifies the annual incidence rate as ranging from 132 to 367 per 100,000 people, with an average rate of 200 brain injuries per 100,000 persons $[15,30]$. The cost of acute and long term medical care for individuals recovering from head injury in the United States is estimated at $\$ 4$ billion dollars per year [31], with an average of $80 \%$ of the lifetime costs incurred during the first year post-injury [21].

\section{Neuropsychological assessment}

Neuropsychologists are frequently called upon to assess brain-injured individuals, and this population comprises the most frequent source of referrals for younger patients (under 40 years of age ) [8]. Primary goals of standardized neuropsychological evaluations include gathering information and gaining insights concerning the specific type and degree of cognitive, behavioral, and neurological problems experienced by individuals. As well, standardized neuropsychological evaluations assist the clinician in formulating a plan for treatment and rehabilitation by identifying the individual's strengths and weaknesses. The results of initial testing illuminate intact functions, reveal impaired functions which need to be addressed in rehabilitation, and provide baseline measures to which future progress can be compared [19]. Neuropsychological

*Address for correspondence: Philip Schatz, Ph.D., Department of Psychology, Saint Joseph's University, Philadelphia, PA 19131, USA. Tel.: +1 610660 1804; Fax: +1 610660 1819; E-mail: pschatz@sju.edu. 
evaluations (NPEs) may be used to determine appropriate employment, school, and residential placement, to assess ability to drive, or to provide evidence of disability in law suits [17]. Neuropsychological screening measures may be used repeatedly to monitor progress in recovery, after which more comprehensive measures can then be used to determine the extent of long-term residual effects [3].

Neuropsychological tests are often used to estimate the eventual outcome (i.e., degree of recovery) following TBI. Factors from neuropsychological assessment of cognitive functioning have been included as predictors of outcome, revealing that patients with deficits in higher-level attentional skills, speed of information processing, non-verbal intellectual skills, and executive functioning had poorer outcomes [7]. However, the ecological validity of neuropsychological measures has been debated [24]. A recent review of the literature on the use of neuropsychological tests to predict everyday functioning revealed no specific neuropsychological measure that could accurately predict a person's everyday functioning following TBI [25].

Previous studies have examined patterns of test usage in NPEs, with different patterns of test usage noted for general clinical psychology evaluations [33], general NPEs [9,29], forensic NPEs [16], and NPEs following moderate-to-severe TBI [11]. While there may be variation in the measures utilized by neuropsychologists, there is little debate regarding their wide-spread use of and reliance on these measures.

\section{Rehabilitation following traumatic brain injury}

Many survivors of traumatic brain injury do not achieve their premorbid level of functioning, and the resultant quality of life varies widely from case to case [8]. The greatest gains in recovery and impact of therapeutic rehabilitation interventions following TBI are believed to occur during a period of time ranging from the first three-to-six months [13] to the first year post-injury [7]. Depending on their ultimate level of functioning, TBI survivors may require long term care involving a supervised living arrangement, may require some type of intermediate care, or may be able to live independently [33]. Thus, the role of the neuropsychologist in documenting an individual's strengths and weaknesses, and integrating these findings into concrete recommendations to guide rehabilitation planning, postrehabilitation vocational, educational and residential placement is crucial.

\section{Managed care}

During the late 1980's and the first half of the 1990's, there has been a substantial shift in the US health care system to "managed care" in order to gain control over health care costs and expenditures. "Managed care" (network-based arrangements) includes health maintenance organizations (HMO's), preferred provider organizations (PPO's), and point-of service (POS) arrangements, all of which have an inherent strong drive to contain costs. Hospitals and insurers operating under managed care systems sometimes impose constraints on service providers, which can jeopardize patient care [18]. While post acute brain injury rehabilitation is found to be generally effective, and thus considered beneficial [20], competition between providers and the push towards cost containment unfortunately result in a need to assess what types of care and treatment are effective and efficient [10].

Analysis of the changes in rehabilitation hospital statistics (for treatment of all diagnoses) from the late 1980 's to early 1990's revealed decreases in number of rehabilitation hospitals and average length of stay. In contrast, increases were noted in the number of patient admissions and overall inpatient days [1,12], suggesting patients of all diagnoses are being admitted to fewer hospitals for shorter stays. Yet, by admitting more patients into the system, the total number of patient days increases. During this same time period, average length of stay in rehabilitation hospitals solely for the treatment of TBI was been reported to increase by one-to-two months [4,5]. We monitored decreases between 1986 and 1993 of 20 days in acute care and 60 days in primary rehabilitation, which was not shown to cause deleterious effects on ultimate level of functional independence for individuals in the study [28]. Despite these apparently neutral systemic changes, specific factors such as length of stay, type and number of rehabilitation admissions, and litigation status have not been evaluated for their effects on neuropsychological practice, cost/benefits analysis, or patient outcomes.

\section{Purpose}

While the utility of formal NPEs following TBI is widely accepted, not every TBI patient receives such an evaluation. This retrospective study attempted to:

- identify factors discriminating between individuals receiving and not receiving NPEs following traumatic brain injury; 
- identify group differences between individuals receiving and not receiving NPEs following traumatic brain injury and whether receiving a NPE improves rehabilitation outcome;

- identify relationships between decade of injury, insurance status, and legal activities on likelihood if receiving a NPE.

\section{Method}

\subsection{Participants}

Participants were 504 individuals considered to be domiciled in the Commonwealth of Pennsylvania (at the time of their head injury) who sustained a traumatic brain injury and applied to the Pennsylvania Head Injury Program (PHIP). All participants met the following definition of traumatic head injury: "an insult to the brain, not of degenerative or congenital nature, but caused by an external physical force that may produce a diminished or altered state of consciousness, which results in impairment of cognitive abilities or physical functioning" [22].

Inclusion in the study required the presence of complete acute care and rehabilitation medical records, evidence of head injury as defined above and documentation of functional ability at least 1.5 years post-injury. Participants were excluded if they were younger than sixteen years of age, if there was evidence of more than one head injury, or evidence of pre-existing conditions (congenital or hereditary birth defects, birth trauma/ asphyxia neonatorum, organic or degenerative brain disorders, or cerebral vascular disorders. An additional control was applied to assure that all participants had an equal opportunity for neuropsychological assessment; to control for time effects, only testing data from within the first three years post injury were included.

The final sample was comprised of 273 participants who meet the above inclusion criteria out of a possible 504 cases.

\subsection{Coding of injury severity, hospitalization, and outcome variables}

Injury severity, hospitalization, and outcome variables were taken directly from individuals' emergency room, acute care, and rehabilitation hospital medical records. Measures included: initial Glasgow Coma Scale (GCS) [32] ratings upon admission to the emergency room, length of loss of consciousness (LOC),
Disability Rating Scale (DRS) [23] scores at discharge from primary rehabilitation, and DRS scores at last measured outcome (i.e., the most recent report in the individual's chart.) When information was not specifically reported scores were extrapolated from medical records (e.g., "decerebrate posturing to pain", or "confused, unintelligible speech" to estimate GCS). Where specific functional ability ratings were not available, information was, when possible, extrapolated from rehabilitation discharge summaries or case manager reports. Inter-rater reliability for this procedure has been established at $0.90[27,28]$.

The duration of LOC was considered to be the first unequivocal sign of responsiveness when an individual followed a command [14]. Thus, LOC was considered to be the period from the date of injury to the date of the following of command, and was coded as 0 (no coma), 1 ( $<20$ minutes), 2 ( $<24$ hours), 3 ( $<1$ week), 4 (120 days), 5 (21-34 days), 6 (35-56 days), or 7 (coma lasting $>8$ weeks).

\subsection{Coding of neuropsychological evaluations}

NPEs were considered to have occurred if reports in the medical records were entitled "neuropsychological" or "psychological" assessment/evaluation, and included the name of at least one formal neuropsychological test. Evaluations conducted over multiple sessions were considered to be one assessment. NPEs s were not coded when tests were administered by nonpsychologists or took place for specified reasons other than a neuropsychological or psychological evaluation, such as within the context of speech therapy or a vocational assessment.

\subsection{Demographics of the sample}

Participants were predominantly young (mean = 29.4 years of age), single ( $61 \%$ single; $21 \%$ divorced/separated) high school educated males (96\%), who sustained TBI's as a result of motor vehicle accidents $(67 \%)$. Participants applied to the PHIP at an average 1.8 years post injury, with either private insurance $(16 \%)$, government assistance in the form of Medicare or Medicaid (44\%), both private and government assistance (15\%), automobile-based insurance in the form of CAT fund or No-fault claims (15\%), or no insurance (10\%). Of those included in this study, 77 (28\%) participants received NPEs within three years post-injury, and $196(72 \%)$ participants did not receive NPEs. 
Table 1

Demographic data for participants

\begin{tabular}{|c|c|c|}
\hline \multicolumn{3}{|l|}{ Gender } \\
\hline Male & 263 & $96.3 \%$ \\
\hline Female & 10 & $3.7 \%$ \\
\hline \multicolumn{3}{|l|}{ Age at Injury } \\
\hline $16-25$ & 125 & $45.8 \%$ \\
\hline $26-35$ & 83 & $30.4 \%$ \\
\hline $36-45$ & 42 & $15.4 \%$ \\
\hline $46+$ & 23 & $8.4 \%$ \\
\hline \multicolumn{3}{|l|}{ Cause of Injury } \\
\hline MVA $^{\mathrm{b}}$ & 149 & $54.7 \%$ \\
\hline Pedestrian $^{\mathrm{c}}$ & 44 & $16.2 \%$ \\
\hline Motorcycle/ATV & 35 & $12.8 \%$ \\
\hline Assault & 29 & $10.7 \%$ \\
\hline Fall & 19 & $7.0 \%$ \\
\hline Other & 12 & $4.4 \%$ \\
\hline \multicolumn{3}{|l|}{ Education } \\
\hline Grades 1-11 & 90 & $33.0 \%$ \\
\hline HS Graduate ${ }^{d}$ & 134 & $49.1 \%$ \\
\hline College & 40 & $14.7 \%$ \\
\hline Graduate School & 4 & $1.5 \%$ \\
\hline Not reported & 5 & $1.8 \%$ \\
\hline \multicolumn{3}{|l|}{ Marital status } \\
\hline Single & 167 & $60.8 \%$ \\
\hline Married & 47 & $17.2 \%$ \\
\hline Divorced & 35 & $12.8 \%$ \\
\hline Separated & 21 & $7.7 \%$ \\
\hline Widow & 3 & $1.1 \%$ \\
\hline \multicolumn{3}{|c|}{ Glasgow Coma Scale in $\mathrm{ER}^{\mathrm{e}}$} \\
\hline 3 to 5 & 155 & $56.8 \%$ \\
\hline 6 to 8 & 46 & $16.8 \%$ \\
\hline 9 to 12 & 14 & $5.1 \%$ \\
\hline 13 to 15 & 18 & $6.6 \%$ \\
\hline Unknown & 44 & $14.7 \%$ \\
\hline \multicolumn{3}{|c|}{ NPEs within 3 years post-injury } \\
\hline Received & 77 & $28.2 \%$ \\
\hline Not received & 196 & $71.8 \%$ \\
\hline
\end{tabular}

${ }^{\mathrm{a}}$ Mean (Standard Deviation).

${ }^{\mathrm{b}} \mathrm{MVA}=$ Motor Vehicle Accidents; includes drivers and passengers.

${ }^{\mathrm{c}}$ Pedestrian $=$ Motor Vehicle Accident pedestrians; included bicyclists hit by automobiles.

${ }^{\mathrm{d}}$ HS Graduate includes Government Equivalent Diploma (GED).

${ }^{\text {e}}$ Glasgow Coma Scale Score at presentation to Emergency Room.

The severity of injury, denoted by mean GCS of 5.45 and mean length of LOC of approximately 2-3 weeks, suggests that this sample is representative of the moderate-to-severe TBI population. Demographic data are presented in Table 1.

\section{Results}

A stepwise discriminant analysis was performed to determine factors affecting which participants received NPEs from the following factors: acute care length of stay, primary rehabilitation hospital length of stay, total hospitalization length of stay, coma severity, length of loss of consciousness, functional ability at discharge from primary rehabilitation, total number of rehabilitation hospitals attended, and ultimate level of independence. Discriminant analysis identified functional ability at discharge from primary rehabilitation and total number of rehabilitation hospitals attended as the two variables that distinguished who received NPEs with $69 \%$ classification accuracy.

Ancillary one-way ANOVAs reveal that individuals who received NPEs within the first three years post injury were younger at the time of their injury $[F(1,271)=10.20, p=0.002]$, spent more time in primary rehabilitation $[F(1,271)=5.29, p=$ 0.022 , significantly higher functional abilities at discharge from primary rehabilitation $[F(1,211)=$ 4.99, $p=0.027]$ and ultimate functional level at outcome $[F(1,235)=4.04, p=0.046]$ than individuals not receiving evaluations. No between group differences were noted in measures of calendar year of injury, coma severity, length of loss of consciousness, and acute care length of stay (Table 2).

Chi-square analyses were conducted to determine whether participants who received NPEs within the first three years post injury were more likely to be involved in liability claims, whether NPEs were more likely to be occur for individuals injured in the 1980's or 1990's, and whether participants with private insurance or government assistance were more likely to receive NPEs. Results indicated that participants receiving NPEs were significantly more likely to be involved in liability claims $(42.7 \%$ vs. $28.3 \%)\left[\chi^{2}(1)=5.10, p=0.024\right]$, more likely to have attended multiple rehabilitation hospitals $(72.7 \%$ vs. $45.9 \%)\left[\chi^{2}(1)=15.69, p=\right.$ $0.000]$ than those not receiving NPEs. Individuals injured from 1985 through 1989 were no more likely to receive NPEs than those injured from 1990 through 1995 (26\% versus $29.5 \%$ ) [ $\left.\chi^{2}(1)=0.38, p=0.54\right]$, despite equal opportunity. Individuals with private insurance were no more likely to receive NPEs than those with government assistance (20.9\% versus $27.5 \%)$ $\left[\chi^{2}(1)=0.71, p=0.40\right]$ (Table 3).

\section{Conclusion}

Following moderate-to-severe traumatic brain injury, only a surprisingly small percentage (28\%) of participants received formal NPEs within the first three years post injury, despite being considered standard practice within this population [10]. The literature is noticeably 
Table 2

Group differences on demographic, injury severity, hospitalization, and outcome variables

\begin{tabular}{|c|c|c|c|c|c|c|c|c|}
\hline \multirow[t]{2}{*}{ Variables } & \multicolumn{3}{|c|}{$\begin{array}{l}\text { Individuals receiving } \\
\text { neuropsych evaluations }\end{array}$} & \multicolumn{3}{|c|}{$\begin{array}{l}\text { Individuals not receiving } \\
\text { neuropsych evaluations }\end{array}$} & \multirow[t]{2}{*}{$\mathrm{p}^{\mathrm{a}}$} & \multirow[t]{2}{*}{$\eta^{\mathrm{b}}$} \\
\hline & $\mathrm{N}$ & Mean & SD & $\mathrm{N}$ & Mean & SD & & \\
\hline \multicolumn{9}{|l|}{ Demographic } \\
\hline Age at injury & 77 & 26.15 & 8.81 & 196 & 30.71 & 11.22 & 0.002 & 0.19 \\
\hline Year of injury & 77 & 90.31 & 2.22 & 196 & 90.16 & 2.48 & 0.43 & \\
\hline \multicolumn{9}{|l|}{ Injury severity } \\
\hline GCS in ER & 64 & 5.45 & 3.12 & 170 & 5.45 & 3.14 & 0.99 & \\
\hline LOC lengthe & 77 & 5.13 & 1.75 & 162 & 4.77 & 1.59 & 0.12 & \\
\hline Acute Care LOS & 77 & 47.32 & 44.23 & 194 & 57.24 & 104.79 & 0.42 & \\
\hline Prim. Rhb LOSd & 77 & 121.16 & 99.86 & 196 & 199.99 & 293.76 & 0.022 & 0.14 \\
\hline \multicolumn{9}{|l|}{ Outcome } \\
\hline DRS at DCe & 61 & 9.43 & 4.98 & 152 & 11.33 & 5.85 & 0.027 & 0.15 \\
\hline DRS last report & 73 & 5.56 & 5.16 & 164 & 7.11 & 5.60 & 0.046 & 0.13 \\
\hline Years-post & 77 & 4.79 & 2.29 & 196 & 4.44 & 2.08 & 0.22 & \\
\hline $\begin{array}{l}{ }^{\mathrm{a}} \text { One-way analyses } \\
{ }^{\mathrm{b}} \eta \text { only reported for } \\
{ }^{\mathrm{c}} \text { LOC }=\text { Loss of Co } \\
{ }^{\mathrm{d}} \text { LOS }=\text { Length of } S \\
{ }^{\mathrm{e}} \text { DRS }=\text { Disability }\end{array}$ & io & $\begin{array}{l}\text { e. } \\
\text { nt findir } \\
\text { ss. }\end{array}$ & & & & & & \\
\hline
\end{tabular}

Table 3

Relationship between neuropsychological evaluations and percent of individuals involved in liability claims, attending multiple rehabilitation hospitalizations and decade of assessment

\begin{tabular}{|c|c|c|c|c|}
\hline & $\begin{array}{c}\text { Individuals receiving } \\
\text { neuropsych evaluations }\end{array}$ & $\begin{array}{l}\text { Individuals not receiving } \\
\text { neuropsych evaluations }\end{array}$ & $\mathrm{p}^{\mathrm{a}}$ & $\phi^{\mathrm{b}}$ \\
\hline Involved in liability claims & $42.7 \%$ & $28.3 \%$ & 0.02 & 0.14 \\
\hline Multiple rehabilitation hospitalizations & $72.7 \%$ & $45.9 \%$ & 0.001 & 0.25 \\
\hline Received NPEs & $\begin{array}{c}\text { Private insurance } \\
20.9 \%\end{array}$ & $\begin{array}{c}\text { Government assistance } \\
27.5 \%\end{array}$ & 0.24 & \\
\hline $\begin{array}{l}\text { Received NPEs } \\
\text { Privately insured }\end{array}$ & $\begin{array}{c}\text { Injured in 1980's } \\
26.0 \% \\
17.0 \%\end{array}$ & $\begin{array}{c}\text { Injured in 1990's } \\
29.5 \% \\
30.2 \%\end{array}$ & $\begin{array}{l}0.54 \\
0.08\end{array}$ & \\
\hline
\end{tabular}

${ }^{\mathrm{a} C h i-s q u a r e}$ analyses.

${ }^{\mathrm{b}} \phi$ only reported for significant findings.

void of such "prevalence of assessment" data, so there is no basis for comparison. However, as individuals recovering from neurotrauma comprise a significant portion of the clientele of neuropsychologists, this number should be of concern.

In this study, functional ability at discharge from primary rehabilitation and number of rehabilitation hospitals attended were the sole discriminating variables between those who did and did not receive NPEs. Individuals receiving NPEs were younger, more likely to be involved in a liability claims, achieved a higher level of functional ability in primary rehabilitation, and attended multiple rehabilitation facilities.

It has been suggested that younger individuals are more likely to receive formal NPEs because of the longstanding belief that they have a better prognosis for recovery of cognitive functioning compared to older individuals [2]. Younger brain injury survivors may also present with more behavioral problems like family difficulties, aggression, or sexual acting out [6] and this may also contribute to increased pressure for formal evaluation.

Severity of injury did not discriminate which individuals received NPEs, as groups were matched on measures of injury severity. One possible explanation for this may be that overt behavioral or emotional problems common to severely head injured patients $[6,8]$ may have been severe enough to eliminate the practicality of NPEs. In this study, individuals receiving NPEs displayed higher functional ratings at discharge from primary rehabilitation, so it appears that there is some form of triage in place. Additionally, the PHIP was intended as a rehabilitation program, not a maintenance program. Prior to admission, an independent evaluator needed to state find credible evidence that progress was 
likely to occur. This would suggest that individuals would not be so severely impaired as to prohibit a NPE.

Our finding that individuals receiving NPEs were more likely to be involved in liability claims supports the notion that neuropsychological tests can (and do) provide evidence of disability [17]. In spite of the fact that individuals receiving NPEs ultimately achieved higher levels of functional ability, a cynical view might wonder if defensive practice is outweighing patient benefit.

Finally, we previously documented an indirect measure of the effects of managed care through observed decreases in acute care and primary rehabilitation length of stay, with no effects on patient outcome [28]. Yet, the current data shows that the likelihood of receiving a NPE and the availability of private insurance did not decreased for individuals injured from 1985-1989 versus 1990-1995. As well, individuals without government assistance in the form of Medicare or Medicaid (rather than private insurance) were no less likely to receive NPEs. While scientific methodology makes it difficult to form a strong conclusion from a null result, it appears that managed care does not appear to be an influential factor affecting the administration of formal NPEs in TBI rehabilitation. Still, it is remarkable that such a low percentage of NPEs are administered in TBI rehabilitation.

It must be noted that the nature of this archival, retrospective study lends to limitations of these findings. As secondary data sources are often utilized in archival studies, the accuracy the data may be questioned [35], and missing or unobtainable data are common. As well, retrospective analyses often lend best to observed relationships rather than causal inferences. However, significant effects and modest effect sizes within a large sample size helps to balance these limitations.

\section{References}

[1] American Hospital Association, American Hospital Association Hospital Statistics, American Hospital Association, Chicago, IL, 1992.

[2] M.R. Bond and D.N. Brooks, Understanding the process of recovery as a basis for the investigation of rehabilitation for the brain injured, Scandinavian Journal of Rehabilitation Medicine 8 (1976), 127-133.

[3] L.I. Cripe, The neuropsychological assessment and management of closed head injury: general guidelines, Cognitive Rehabilitation 5 (1987), 18-22.

[4] E.R. Dahmer, M.A. Shilling, B.B. Hamilton, C.F. Bontke, J. Englander, J.S. Kreutzer, K.T. Ragnarsson and M. Rosenthal, A model systems database for traumatic brain injury, Journal of Head Trauma Rehabilitation 8 (1993), 12-25.
[5] H.K. Do, D.A. Sahagian, L.C. Schuster and S.E. Sheridan, Head trauma rehabilitation: program evaluation, Rehabilitation Nursing 13 (1988), 71-75.

[6] W. Gardner, P. Schatz, F.G. Hillary and D.L. Chute, The effect of behavioral, personality, and emotional changes after brain injury on caregiver relationships, Archives of Clinical Neuropsychology 14 (1999), 779.

[7] D. Girard, J. Brown, M. Burnett-Stolnack, N. Hashimoto, S. Hier-Wellmer, O.Z. Perlman and C. Seigerman, The relationship of neuropsychological status and productive outcomes following traumatic brain injury, Brain Injury 10 (1996), 663676.

[8] C.J. Golden, J.A. Moses Jr., J.A. Coffman, W.R. Miller and F.D. Strider, Head injury, in: Clinical Neuropsychology, Grune \& Stratton, Orlando, FL, 1983, pp. 35-53.

[9] T.J. Guilmette, D. Faust, K. Hart and H.R. Arkes, A national survey of psychologists who offer neuropsychological services, Archives of Clinical Neuropsychology 5 (1990), 373392.

[10] D.P. Harris, Outcome measures and a program evaluation model for postacute brain injury rehabilitation, Journal of Rehabilitation Outcomes Measurement 1 (1997), 23-30.

[11] T. Horowitz, P. Schatz and D.L. Chute, Trends in neuropsychological test usage, Archives of Clinical Neuropsychology 12 (1997), 281

[12] Hospital Financial Report, Hospital Utilization: 1989, in: 1992 Pennsylvania Abstract, PA Data Center, Penn State, Institute of State and Regulatory Affairs, Harrisburg, PA, 1989.

[13] B. Jennett, Scale and Scope of the Problem, in: Rehabilitation of the Head Injured Adult, M. Rosenthal, E.R. Griffith, M.R. Bond and J.D. Miller, eds, F.A. Davis Company, Philadelphia, PA, 1983, pp. 291-308.

[14] D.L. Katz and M.P. Alexander, Traumatic brain injury: predicting course of recovery and outcome for patients admitted to rehabilitation, Archives of Neurology, 15 (1994), 661-670.

[15] J.F. Kraus, Epidemiology of head injury, in: Head Injury, (3rd ed.), P.R. Cooper, ed., Williams \& Wilkins, Baltimore, MD, 1993, pp. 1-25.

[16] P.R. Lees-Haley, H.H. Smith, C.W. Williams and J.T. Dunn, Forensic neuropsychological test usage: an empirical survey, Archives of Clinical Neuropsychology 11 (1996), 45-51.

[17] M.D. Lezak, Neuropsychological Assessment, (3rd ed.), University Press, New York, Oxford Valley, 1995.

[18] D.W. Light, Managed care, American Journal of Psychiatry 154 (1996), 443.

[19] W.J. Lynch, Neuropsychologic Assessment, in: Rehabilitation of the Head Injured Adult, M. Rosenthal, E.R. Griffith, M.R. Bond and J.D. Miller, eds, F.A. Davis Company, Philadelphia, PA, 1983, pp. 291-308.

[20] J.F. Malec and J.S. Basford, Postacute brain injury rehabilitation, Archives of Physical Medicine Rehabilitation 77 (1996), 198-207.

[21] W. Max, E.J. MacKenzie and D.P. Rice, Head injuries: Costs and consequences, Journal of Head Trauma Rehabilitation 6 (1991), 76-91.

[22] A.J. Molitor, Pennsylvania's Head Injury Services, Health Reporter 11 (1990), 1-2.

[23] M. Rappaport, K.M. Hall, K. Hopkins, T. Belleza and D.N. Cope, Disability rating scale for severe head trauma patients: Coma to community, Archives of Physical Medicine Rehabilitation 16 (1982), 118-123.

[24] R.J. Sbordone, Ecological validity issues in neuropsychological testing, Brain Injury Source 4 (2000), 10-12. 
[25] R.J. Sbordone and T.J. Guilmette, Ecological validity: Prediciton of everyday and vocational functioning from neuropsychological test data, in: Forensic Neuropsychology: Fundamentals in Practice, J.J. Sweet, ed., Swets \& Zeitlinger, Lisse, Netherlands, 1999, pp. 227-254.

[26] P. Schatz, Predicting level of independence following moderate-to-severe traumatic brain injury, Unpublished Doctoral Dissertation, Drexel University, 1995.

[27] P. Schatz, F.G. Hillary and D.L. Chute, Predicting functional outcome with Disability Rating Scale scores following primary rehabilitation: What you see is what you get, Archives of Clinical Neuropsychology 13 (1998), 147-148.

[28] P. Schatz and D.L. Chute, Predicting level of independence following moderate-to-severe traumatic brain injury, Archives of Clinical Neuropsychology 11 (1996), 444-445.

[29] M.L. Seretny, R.S. Dean, J.W. Gray and L.C. Hartlage, The practice of clinical neuropsychology in the United States, Archives of Clinical Neuropsychology 1 (1986), 5-12.
[30] S.B. Sorenson and J.F. Kraus, Occurrence, severity, and outcomes of brain injury, Journal of Head Trauma Rehabilitation 6 (1991), 1-10.

[31] D.M. Sosin, J.E. Sniezek and D.J. Thurman, Incidence of mild and moderate brain injury in the United States, Brain Injury 10 (1996), 46-54.

[32] G. Teasdale and B. Jennett, Assessment of coma and impaired consciousness: a practical scale, Lancet 2 (1974), 81-83.

[33] T.C. Wade and T.B Baker, Opinions and use of psychological tests: a survey of clinical psychologists, American Psychologist 32 (1977), 874-882.

[34] G.R. Wolfe, Clinical neuropsychology and assessment of brain impairment: an overview, Cognitive Rehabilitation 5 (1987), 20-25.

[35] J.W. Luckey, A. Broughton and J.E. Sorensen, Archival data in program evaluation and policy analysis, Evaluation and Program Planning 5 (1982), 319-326. 